\title{
Quality-Control Design for Surface-Water Sampling in the National Water-Quality Assessment Program
}

U.S. GEOLOGICAL SURVEY

Open-File Report 97-223

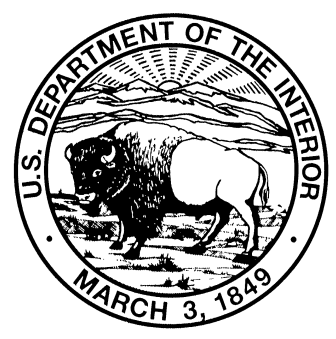




\section{Quality-Control Design for Surface-Water Sampling in the National Water-Quality Assessment Program}

By David K. Mueller, Jeffrey D. Martin, and Thomas J. Lopes

U.S. GEOLOGICAL SURVEY

Open-File Report 97-223

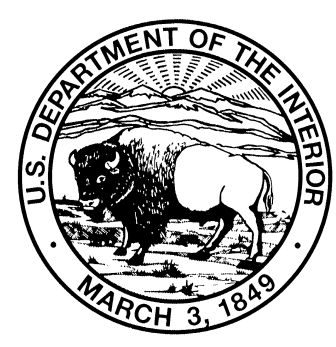




\title{
U.S. DEPARTMENT OF THE INTERIOR BRUCE BABBITT, Secretary
}

\author{
U.S. GEOLOGICAL SURVEY \\ Gordon P. Eaton, Director
}

The use of firm, trade, and brand names in this report is for identification purposes only and does not constitute endorsement by the U.S. Geological Survey.

For additional information write to:

Chief, NAWQA Program

U.S. Geological Survey

12201 Sunrise Valley Drive

Mail Stop 413

Reston, VA 20192
Copies of this report can be purchased from:

U.S. Geological Survey

Information Services

Box 25286

Federal Center

Denver, CO 80225

Information regarding the National Water-Quality Assessment (NAWQA) Program is available on the Internet via the World Wide Web. You may connect to the NAWQA Home Page using the Universal Resources Locator (URL) at http://wwwrvares.er.usgs.gov/nawqa/nawqa_home.html> 


\section{FOREWORD}

The mission of the U.S. Geological Survey (USGS) is to assess the quantity and quality of the earth resources of the Nation and to provide information that will assist resource managers and policymakers at Federal, State, and local levels in making sound decisions. Assessment of water-quality conditions and trends is an important part of this overall mission.

One of the greatest challenges faced by waterresources scientists is acquiring reliable information that will guide the use and protection of the Nation's water resources. That challenge is being addressed by Federal, State, interstate, and local water-resource agencies and by many academic institutions. These organizations are collecting water-quality data for a host of purposes that include: compliance with permits and water-supply standards; development of remediation plans for specific contamination problems; operational decisions on industrial, wastewater, or watersupply facilities; and research on factors that affect water quality. An additional need for water-quality information is to provide a basis on which regionaland national-level policy decisions can be based. Wise decisions must be based on sound information. As a society we need to know whether certain types of water-quality problems are isolated or ubiquitous, whether there are significant differences in conditions among regions, whether the conditions are changing over time, and why these conditions change from place to place and over time. The information can be used to help determine the efficacy of existing water-quality policies and to help analysts determine the need for and likely consequences of new policies.

To address these needs, the U.S. Congress appropriated funds in 1986 for the USGS to begin a pilot program in seven project areas to develop and refine the National Water-Quality Assessment (NAWQA) Program. In 1991, the USGS began full implementation of the program. The NAWQA Program builds upon an existing base of water-quality studies of the USGS, as well as those of other Federal, State, and local agencies. The objectives of the NAWQA Program are to:

- Describe current water-quality conditions for a large part of the Nation's freshwater streams, rivers, and aquifers.
- Describe how water quality is changing over time.

- Improve understanding of the primary natural and human factors that affect water-quality conditions.

This information will help support the development and evaluation of management, regulatory, and monitoring decisions by other Federal, State, and local agencies to protect, use, and enhance water resources.

The goals of the NAWQA Program are being achieved through ongoing and proposed investigations of 59 of the Nation's most important river basins and aquifer systems, which are referred to as study units. These study units are distributed throughout the Nation and cover a diversity of hydrogeologic settings. More than two-thirds of the Nation's freshwater use occurs within the 59 study units and more than twothirds of the people served by public water-supply systems live within their boundaries.

National synthesis of data analysis, based on aggregation of comparable information obtained from the study units, is a major component of the program. This effort focuses on selected water-quality topics using nationally consistent information. Comparative studies will explain differences and similarities in observed water-quality conditions among study areas and will identify changes and trends and their causes. The first topics addressed by the national synthesis are pesticides, nutrients, volatile organic compounds, and aquatic biology. Discussions on these and other waterquality topics will be published in periodic summaries of the quality of the Nation's ground and surface water as the information becomes available.

This report is an element of the comprehensive body of information developed as part of the NAWQA Program. The program depends heavily on the advice, cooperation, and information from many Federal, State, interstate, Tribal, and local agencies and the public. The assistance and suggestions of all are greatly appreciated. (signed)

Robert M. Hirsch

Chief Hydrologist 


\section{CONTENTS}

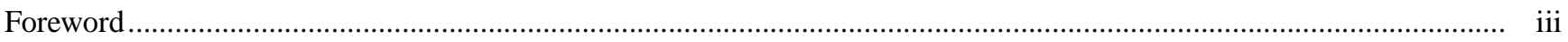

Abstract

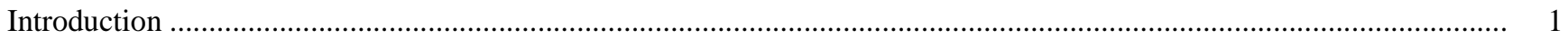

Purpose and Scope

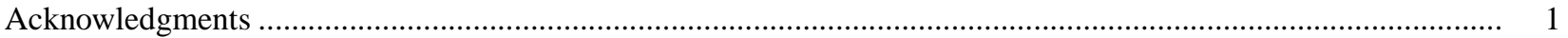

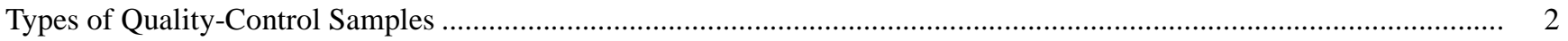

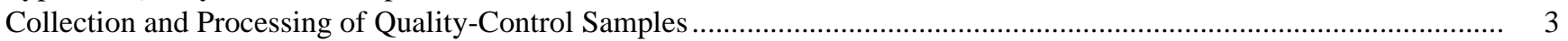

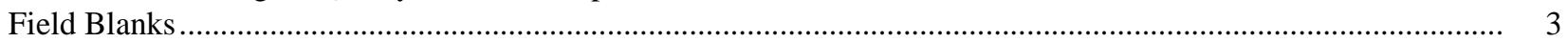

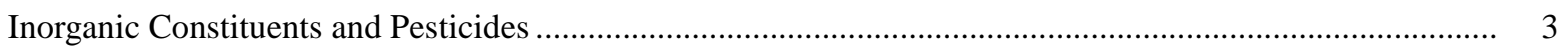

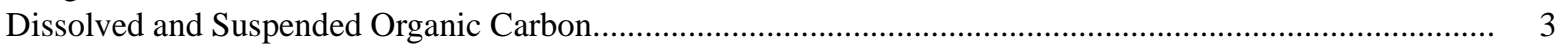

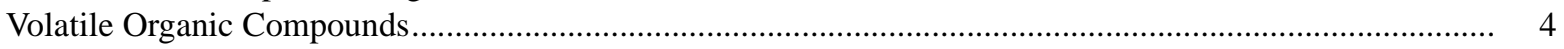

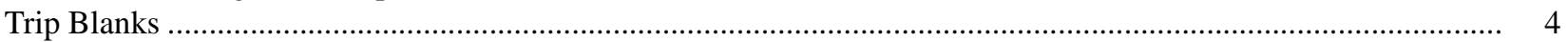

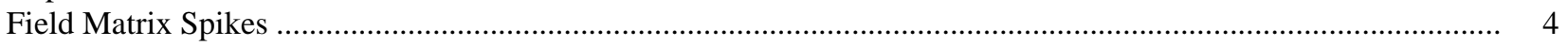

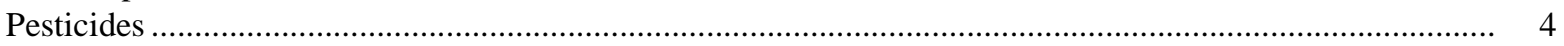

Volatile Organic Compounds............................................................................................................ 5

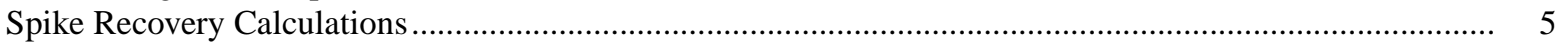

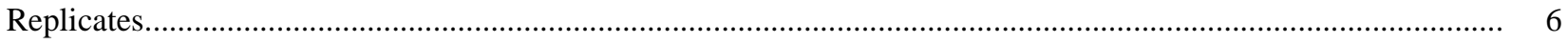

Inorganic Constituents, Pesticides, and Suspended Sediment........................................................................ 6

Dissolved and Suspended Organic Carbon................................................................................................ 6

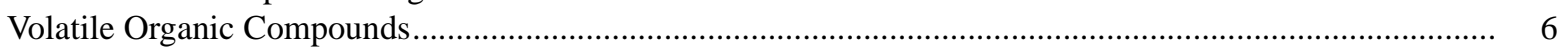

Frequency, Timing, and Location of Quality-Control Sample Collection ................................................................

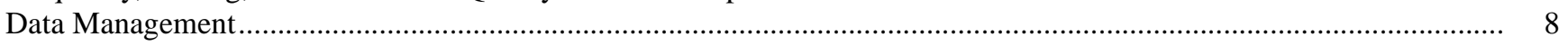

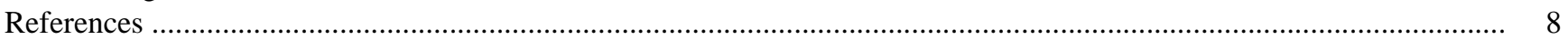

Appendix A-Constituents Included in National Water Quality Laboratory Schedules and Codes

Referred to in this Report......

Appendix B-Analytical Services Request and National Water Information System Data-Base

Coding Required for Quality-Control Samples and Associated Environmental Samples

Collected as Part of the National Water-Quality Assessment Program............................................................. 15

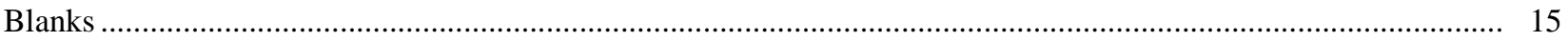

Environmental Sample Associated with the Blank .............................................................................. 15

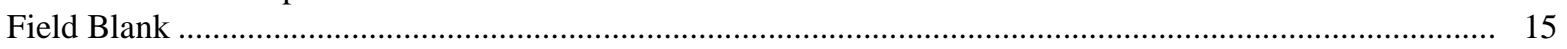

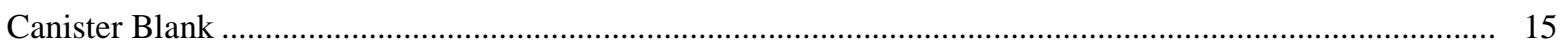

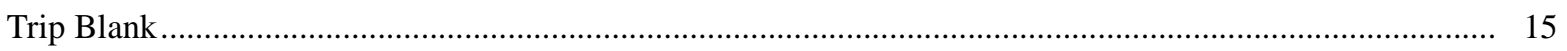

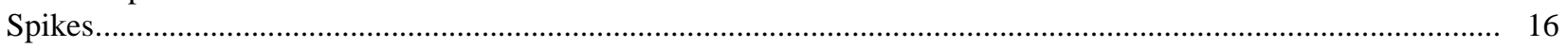

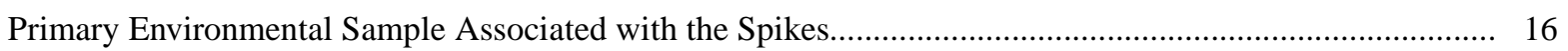

Duplicate Environmental Sample Associated with the Spikes ................................................................ 16

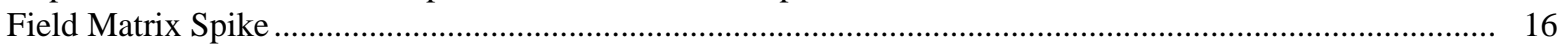

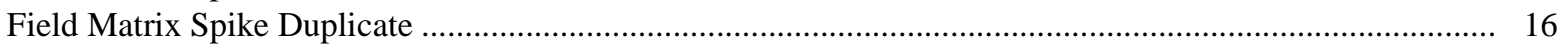

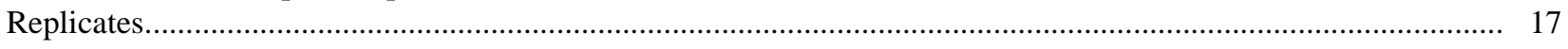

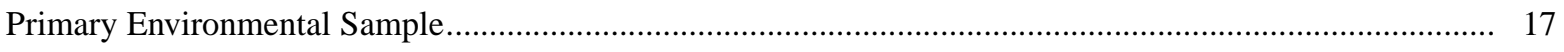

Duplicate Environmental Sample ………............................................................................................ 17

\section{TABLES}

1. Collection frequencies for routine quality-control samples ........................................................................ 7

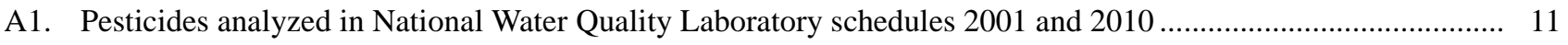

A2. Pesticides analyzed in National Water Quality Laboratory schedules 2050 and 2051 .................................... 12

A3. Volatile organic compounds analyzed in National Water Quality Laboratory schedule 2020 ............................ 13 


\section{CONVERSION FACTORS AND ABBREVIATIONS}

\begin{tabular}{lll}
\hline Multiply & By & To obtain \\
\hline & & \\
$\operatorname{liter}(\mathrm{L})$ & 1.057 & quart \\
$\operatorname{liter}(\mathrm{L})$ & 0.2642 & gallon \\
gram (g) & 0.03527 & ounce, avoirdupois
\end{tabular}

\section{Additional Abbreviations}

milliliter $(\mathrm{mL})$

microliter $(\mu \mathrm{L})$

milligram per liter $(\mathrm{mg} / \mathrm{L})$

microgram per liter $(\mu \mathrm{g} / \mathrm{L})$

microgram per milliliter $(\mu \mathrm{g} / \mathrm{mL})$ 


\title{
Quality-Control Design for Surface-Water Sampling in the National Water-Quality Assessment Program
}

\author{
By David K. Mueller, Jeffrey D. Martin, and Thomas J. Lopes
}

\begin{abstract}
The data-quality objectives of the National Water-Quality Assessment Program include estimating the extent to which contamination, matrix effects, and measurement variability affect interpretation of chemical analyses of surfacewater samples. The quality-control samples used to make these estimates include field blanks, field matrix spikes, and replicates. This report describes the design for collection of these quality-control samples in National Water-Quality Assessment Program studies and the data management needed to properly identify these samples in the U.S. Geological Survey's national data base.
\end{abstract}

\section{INTRODUCTION}

A primary goal of the National Water-Quality Assessment (NAWQA) Program is to describe the occurrence, distribution, and trends of selected chemical constituents in the Nation's surface and ground water. To interpret water-quality data properly, information is needed to estimate the bias and variability that result from sample collection, sample processing, and chemical analysis. Bias is the systematic error inherent in a method and may be either positive or negative. Variability is the degree of random error in repeated measurements of the same quantity.

The objectives in evaluating sampling bias and variability for surface-water chemical analyses are to determine the extent to which:

1. Sampling methods and equipment introduce contaminants (positive bias) into water samples.
2. Sample-matrix interference or analyte degradation affect the recovery (bias and variability) of organic compounds.

3. Sample collection, processing, and analysis affect the variability of measured constituent concentrations.

Data obtained from routine quality-control (QC) samples are used by NAWQA study-unit and national-synthesis teams to meet these objectives and to evaluate potential effects on the interpretation of environmental data.

\section{Purpose and Scope}

This report describes:

1. Procedures used to collect QC samples at surfacewater sites in the NAWQA Program.

2. Sampling design, including frequency, timing, and location of sample collection.

3. Data management, including coding used to submit samples for laboratory analysis and to store results in electronic data bases.

The scope is limited to NAWQA study units that began operation in 1994 or that are to begin later.

The first surface-water samples in these study units were collected during 1995-96.

\section{Acknowledgments}

The procedures and sampling design described in this report were developed in extensive discussions by the NAWQA QC Workgroup. The authors acknowledge the substantial contributions of other members of the Workgroup: Michael Koterba (Project Chief), Greg Delzer, Kimberly Pirkey, Barbara Ruddy, Terry Schertz, and Jonathan Scott. 


\section{TYPES OF QUALITY-CONTROL SAMPLES}

Three types of QC samples are routinely collected in NAWQA studies. Blanks and spikes are used to estimate bias. Replicates are used to estimate variability.

A blank is a water sample that is intended to be free of the analytes of interest. Blank samples are analyzed to test for bias that could result from contamination of environmental samples by the analytes of interest during any stage of sample collection, processing, and analysis. A field blank is prepared in the field and used to demonstrate that: (1) Equipment has been adequately cleaned to remove contamination introduced by samples obtained at previous sites, (2) sample collection and processing have not resulted in contamination, and (3) sample handling and transport have not introduced contamination. In addition, because the field blank is treated like an environmental sample at the laboratory, it includes potential contamination introduced during laboratory handling and analysis.

An equipment blank is used to demonstrate that the sample-collection and sample-processing equipment is not introducing contamination.

Equipment blanks can be prepared using individual pieces of the collection and processing equipment. For example, a sample prepared by exposing the blank solution just to the filter apparatus would be a filter blank. In the NAWQA Program, the only type of equipment blank that is routinely prepared is a canister blank, which is collected from the canister used to prepare volatile organic compound (VOC) blanks. It is used to determine whether the canister is introducing contamination into the VOC field blank in excess of that which might be introduced by the VOC sampler itself. A canister blank is prepared only in association with a VOC field blank.

A trip blank is a sample of analyte-free water that is prepared in the laboratory or in the office. It is transported, unopened, to the field with other sample bottles and is shipped to the laboratory for analysis with the collected samples. Trip blanks are used to identify contamination that might occur during sample transport and analysis rather than as a result of sample collection and processing in the field. Because the primary source of this contamination is airborne, trip blanks are normally prepared only for VOC's.

A spike is an environmental sample that is fortified with a known mass of the analyte of interest. Spiked samples are used to test for bias resulting from matrix interference or analyte degradation. Matrix interference is the effect that the sample matrix has on measurement of individual analytes within the sample. A field matrix spike is a specific type of spiked sample that is fortified in the field prior to shipping. These samples are used to assess the potential bias for analytes in a particular sample matrix. This bias also might include analyte degradation during shipping and handling. Bias is estimated from spiked samples by calculating the percentage of the added analyte that is measured (recovered) in the sample. Recovery can be either greater than or less than 100 percent, so the bias can be either positive or negative; however, matrix interference and analyte degradation generally result in a negative bias.

Replicates are two or more samples collected or processed so that the samples are considered to be essentially identical in composition. Split replicates are prepared by dividing a single volume of water into multiple samples. These replicates provide a measure of the variability introduced during sample processing and analysis. Concurrent replicates are multiple samples collected from an environmental matrix as closely as possible to the same location and time. These replicates account for the variability measured by split replicates and the additional variability introduced by sample collection. Depending on sampling procedures, concurrent replicates also might include an unknown amount of short-term environmental variability. Sequential replicates are multiple samples collected at the same location, but at slightly different times, generally one right after the other. These replicates provide a measure of the same sources of variability as concurrent replicates and the additional variability associated with short-term environmental fluctuation.

For the purposes of this report, the term "replicates" is used to refer to all similarly collected or processed samples. The terms "primary environmental sample" and "duplicate environmental sample" are used to identify particular samples in a replicate pair. Likewise, the term "field matrix spike replicates" is used to refer to all similarly collected, processed, and spiked samples, and the terms "field matrix spike" or "field matrix spike duplicate" are used to identify particular spiked samples. The term "subsample" refers to that portion of any individual sample (or duplicate) that is processed for analysis of a particular group of analytes (such as anions, cations, dissolved nutrients, or pesticides). 


\section{COLLECTION AND PROCESSING OF QUALITY-CONTROL SAMPLES}

\section{Field Blanks}

Field blanks should be prepared immediately before collecting and processing an environmental sample at a selected site. All equipment should have been cleaned, either in the field or in the laboratory, following use at the previous site. Shelton (1994, p. 13) describes the cleaning procedure.

The water used for NAWQA field blanks must be either Ocala inorganic-grade (IG) deionized water, National Water Quality Laboratory (NWQL) pesticide-grade (PG) water, or NWQL volatile-grade (VG) water. Pesticide blanks must be prepared from PG water. Dissolved organic carbon (DOC) and suspended organic carbon (SOC) blanks can be prepared using either PG water or VG water. The VOC blanks must be prepared from VG water. The DOC, SOC, and VOC blanks must be prepared using water from a previously unopened (fresh) bottle. Opened bottles might no longer be free of organiccarbon species.

To avoid the necessity of rinsing equipment with both IG water and PG water, field blanks for inorganic constituents should not be prepared during the same site visit as field blanks for pesticides. In addition, preparing the first blank could remove most of the residual contamination, so the second blank might not be representative. To avoid data-base conflicts in specifying the type of blank water, field blanks prepared for different organic constituents using different grades of water at the same site visit must be assigned different times and submitted with separate Analytical Services Request (ASR) forms.

Equipment need not be cleaned nor filters changed between processing the field blank and the environmental sample. Simply field rinse with native water as would normally be done. However, certain pieces of equipment should be cleaned if they have obviously been contaminated or if there is a significant potential for contamination, such as a sample splitter sitting exposed to the environment for a long period of time.

\section{Inorganic Constituents and Pesticides}

1. Rinse all equipment with the appropriate type of blank water (IG or PG). Follow the procedures normally used for field rinsing.

2. Obtain a field-blank sample by pouring the blank water into the bottle used with a US DH-81 or US D-77 sampler (Edwards and Glysson, 1988). Cap and shake. If environmental samples normally are composited, pour about $0.5 \mathrm{~L}$ of blank water from the sampler bottle through the sampler cap and nozzle into the compositing container. Pouring through the sampler cap and nozzle simulates water contact with these components during sample collection. Then pour additional blank water directly from the sampler bottle into the compositing container until there is sufficient volume to prepare all the necessary subsamples. If environmental samples normally are poured directly into a U.S. Geological Survey (USGS) Teflon cone splitter (Capel and Larson, 1996), pour about $0.5 \mathrm{~L}$ of blank water through the sampler cap and nozzle into the splitter. Then pour additional blank water directly from the sampler bottle into the cone splitter to fill the subsample containers. If multiple sampler bottles are used to collect samples, pour some blank water from each bottle into the compositing container or cone splitter.

3. Process the subsamples according to normal procedures for a surface-water site (Shelton, 1994, p. 20 and p. 23-26). Rinse sample bottles and filters following normal procedures, using blank water instead of native water.

4. Record the lot number of the blank water in field notes and on the Comments line of the ASR form. Also, record the last site and date at which the sampling equipment was used so this possible source of contamination can be identified.

\section{Dissolved and Suspended Organic Carbon}

Rinse a new, laboratory-baked sampler bottle, such as normally used to collect the single-vertical organic-carbon sample, with blank water. Fill the sampler bottle with fresh PG or VG water. Process the blank according to the DOC/SOC procedure for samples containing less than $30 \mathrm{mg} / \mathrm{L}$ suspended sediment (Shelton, 1994, p. 21). 


\section{Volatile Organic Compounds}

1. Rinse the VOC hand-sampler and the steel transport canister (supplied by VOC National Synthesis) three times with fresh VG water.

2. While wearing vinyl gloves, uncap six $40-\mathrm{mL}$ vials. Set two vials aside for the canister blank; place the remaining four vials into the sampler. Do not label the vials until sample processing has been completed.

3. Fill the transport canister with fresh VG water.

4. Submerge and fill the two canister-blank vials in the canister.

5. Submerge the sampler in the canister and fill the remaining four vials. Select three of these vials to use for the field blank.

6. Preserve, cap, and process both blanks according to the procedure used for environmental samples (L.R. Shelton, U.S. Geological Survey, written commun., 1996).

\section{Trip Blanks}

Trip blanks are used only for VOC's. Pre-filled vials of VG water, prepared at the NWQL, can be special ordered from the laboratory. Also, trip blanks can be included with regular orders for $40-\mathrm{mL}$ sample vials, if requested.

Trip blanks can become contaminated when stored for long periods. To avoid this problem, pre-filled blanks should be stored in sealed containers, such as clean mason jars, and should be used within 1 week. Thus, blanks should not be ordered until just before they are intended to be used.

Select three pre-filled vials to be the trip blank and transport them to the field with the other VOC vials. Label the trip-blank vials with the same site number and date as used for a field blank prepared during the sampling trip. Ship the trip blank to the laboratory with the field blank and the environmental samples from that site. Do not open the trip-blank vial at any time.

\section{Field Matrix Spikes}

Field matrix spikes are required for pesticides (NWQL schedules 2001, 2010, 2050, and 2051) and for VOC's (NWQL schedule 2020).
(Compounds included in these pesticide schedules and VOC schedule 2020 are listed in appendix A.) Spikes are always prepared in duplicate and require at least one environmental sample to estimate background concentrations of the spiked analytes. If detectable background concentrations of the spiked analytes are expected, replicate environmental samples should be collected to provide more precise estimates of background concentrations.

Pesticide spikes are split replicates from an environmental sample. The VOC spikes are sequential replicates of an environmental sample. For all routine spiked samples, the spiking solution should be added in the field, even if extraction is done at the NWQL. Spike kits and solutions must be obtained from the NWQL and should be used within 2 months. Always store spike solutions in a refrigerator or on ice to minimize degradation, and discard unused solution after opening.

\section{Pesticides}

1. Collect a sample using normal procedures (Shelton, 1994, p. 14). Obtain enough water for the extra pesticide subsamples. The necessary volume depends on the number of environmental samples that will be used to estimate background concentrations (one or two) and on the pesticides that will be spiked (schedules 2001/2010 or 2050/2051, or both). At least an additional 6 L of water are required if spikes are prepared for both pesticide schedules and if replicate environmental samples are collected.

2. Split the sample using a USGS Teflon cone splitter. Obtain three subsamples for pesticide analysis (or four subsamples if replicate environmental samples are needed). Use one of these subsamples to prepare the environmental sample, use another to prepare the duplicate environmental sample (if needed), and use the remaining two subsamples to prepare replicate field matrix spikes.

3. Filter the environmental sample following normal procedures (Shelton, 1994, p. 23).

4. If replicate environmental samples are needed, load and rinse a new filter, and filter the duplicate environmental sample. 
5. Filter the subsample replicates that are to be spiked following the same procedures used for the environmental sample. Use a new filter for each replicate to minimize the variability associated with filter loading. Filter approximately the same volume of water for each replicate. After filtering and before extraction, add $0.1 \mathrm{~mL}(100 \mu \mathrm{L})$ of the appropriate spike solution to each replicate using a micropipette (ignore instructions in the spike kit about NWQL spiking one of the replicates in the laboratory). Use a new micropipette for each spike. Allow the spike solution to warm to room temperature before spiking.

6. Finish processing the environmental sample (and duplicate) and spiked replicates. For each spiked replicate, record the lot number of the spike solution, the volume (milliliters) of spike solution used, and the volume (milliliters)

of the spiked subsample in field notes and on the Comments line of the ASR form. (This information is necessary for computing spike recovery.)

\section{Volatile Organic Compounds}

1. Load four 40-mL vials into the VOC hand-sampler and collect a sample. Three of these vials constitute the environmental sample, and one vial is used for backup if bubbles are present in one of the other vials after processing. If replicate environmental samples are needed to estimate background concentrations, two of the vials will constitute the primary environmental sample and the other two will constitute the duplicate environmental sample.

2. Process and cap the environmental samples following normal procedures (L.R. Shelton, U.S. Geological Survey, written commun., 1996). If replicate environmental samples are needed, note on each ASR form that only two vials have been submitted (instead of the usual three).

3. Immediately load four additional vials and collect another sample. These vials will constitute the spiked replicates (two vials each).

4. Following the instructions provided with the spiking kit, use a syringe to inject the spike solution into the four spike-replicate vials. Do not inject the spike solution through the septum in the cap. Minimize the time that the vial is uncapped, exposing the sample to volatilization loss.

5. Process both spiked replicates following the same procedures used for the environmental sample. Label the first two spiked vials with FS (field spike) and the second two spiked vials with FSD (field spike duplicate).

6. On the ASR forms for each spiked replicate, record that only two vials have been submitted. Record the lot number of the spike solution and the volume of spike solution in field notes and on the Comments line of the ASR forms. (This information is necessary for computing spike recovery.)

\section{Spike Recovery Calculations}

Spike recovery (percent) for pesticides and VOC's is calculated as follows:

$$
\text { Recovery }=100 \cdot \frac{C_{\text {Spiked }}-C_{\text {Environ }}}{C_{\text {Expect }}}
$$

where

$$
\begin{aligned}
C_{\text {Spiked }}= & \text { the measured concentration in the spiked } \\
& \text { sample, in micrograms per liter; } \\
C_{\text {Environ }}= & \text { the measured concentration in the } \\
& \text { associated environmental sample, in } \\
& \text { micrograms per liter, or the mean } \\
& \text { concentration in the associated replicate } \\
& \text { environmental samples, in micrograms per } \\
& \text { liter; and } \\
C_{\text {Expect }}= & \text { the expected concentration of the spike in } \\
& \text { the spiked sample, in micrograms per liter. }
\end{aligned}
$$

The expected concentration is calculated as follows:

$$
C_{\text {Expect }}=1,000 \cdot \frac{C_{\text {Soln }} \times V_{\text {Soln }}}{V_{\text {Samp }}}
$$

where

$C_{\text {Soln }}=$ the concentration of the spike solution, in micrograms per milliliter;

$V_{\text {Soln }}=$ the volume of spike solution added to the sample, in milliliters; and

$V_{\text {Samp }}=$ the volume of the sample, in milliliters. 


\section{Replicates}

Replicates for analysis of inorganic constituents, pesticides, and suspended sediment are produced by splitting a single, large volume of water, collected from the stream, into two samples (one primary and one duplicate). Replicates for DOC, SOC, and VOC's are collected from concurrent grab samples (a sample splitter is not used for these analytes). The reason for selecting split replicates for most analytes is to exclude variability caused by short-term environmental fluctuations, which might affect sequential replicates and, to some degree, concurrent replicates. Split replicates allow assessment of sources of variability (sample processing, handling, and analysis) that can be controlled by field and laboratory procedures. Topical (nonroutine) QC samples are collected at selected sites to assess the variability caused by sample collection (Timothy L. Miller, U.S. Geological Survey, written commun., 1996). These samples require the collection of concurrent replicates by different field crews during targeted conditions.

Study units need to procure additional 3-L Teflon sampler bottles and 2-L glass split containers to collect and process sufficient volumes of water for split-replicate samples.

The split replicates (primary and duplicate samples) are processed sequentially by analyte group (major ions, nutrients, trace elements, or pesticides). Sequential processing minimizes the variability caused by differences in holding times of the primary and duplicate samples.

\section{Inorganic Constituents, Pesticides, and Suspended Sediment}

1. Collect a volume of stream water large enough for all subsamples that are obtained for the primary and duplicate samples. Often, this volume is double the amount normally collected.

2. Rinse a USGS Teflon cone splitter and large split containers with native water. Pour the water collected from the stream through the cone splitter into two sets of containers. One set is used for the primary sample, and the other is used for the duplicate sample. Do not mix water between the two sets of containers. Place the containers for the duplicate sample on ice in a cooler.
3. Rinse the cone splitter and additional split containers with native water. Split the primary sample as is normally done to obtain the necessary whole-water subsamples and additional subsamples to be filtered later. Place these subsamples in a second cooler.

4. Repeat step 3 for the duplicate sample. Place the resultant subsamples in the first cooler.

5. Filter the subsamples in the normal order used for the different analyte groups (major ions, nutrients, trace elements, or pesticides). For each group, filter the primary sample first, then the duplicate sample. Filter the primary sample for all analyte groups that normally use the same filter (for example, nutrients and major ions) before proceeding to the duplicate sample. Load and rinse new filters prior to filtering the duplicate sample. Do not clean the equipment between samples.

6. Sometimes only selected analyte groups are obtained from the duplicate sample (for example, pesticides, but not inorganic constituents). A suspended-sediment analysis should be obtained from every duplicate sample.

7. Make separate field measurements of $\mathrm{pH}$, specific conductance, and alkalinity in the primary and duplicate samples.

\section{Dissolved and Suspended Organic Carbon}

1. Collect grab samples in two glass bottles following normal procedures for organic-carbon sampling (Shelton, 1994). Minimize the time interval between the two grabs. These samples are considered concurrent for the purposes of data management.

2. Store the duplicate sample in a cooler. Process the primary sample according to normal procedures. Rinse the filter holder with PG or VG water between samples to remove any sediment. Then, process the duplicate sample.

\section{Volatile Organic Compounds}

1. Load four 40-mL vials into the VOC hand-sampler and collect a sample.

2. Process two vials as the primary sample and the other two as the duplicate sample. Process the primary sample first, then the duplicate sample, following normal procedures. On each ASR form, record that only two vials have been submitted (instead of the usual three). 


\section{FREQUENCY, TIMING, AND LOCATION OF QUALITY-CONTROL SAMPLE COLLEC- TION}

The minimum number of each type of QC sample required to meet the stated $\mathrm{QC}$ objectives is listed in table 1. The criteria used in determining this sampling distribution are based on characteristics of the constituents, expected constituent concentrations in surface waters of the study unit, and results of previous QC analyses. The minimum numbers can be increased if necessary to meet individual study-unit objectives.

The first field blank should be collected as soon as a sampling routine has been established. Subsequent field blanks should be collected throughout the sampling period in proportion to the number of environmental samples. Field blanks can be prepared at any surface-water site; however, certain sites should be targeted to test the greatest potential risk of contamination (for example, sites sampled following use of the equipment in water with high analyte concentrations). Field blanks do not need to be prepared at every surface-water site. If surfacewater samples are collected by more than one sampling team, each team should prepare a number of blanks throughout the year in proportion to the number of surface-water samples the team collects. The goal is to evaluate each sampling team and each equipment set often enough to ensure that procedures are adequate or that corrective actions are taken.

Trip blanks for VOC's should be shipped for analysis with selected field blanks. Because field vehicles contain various sources of VOC's (such as adhesives and gasoline) that might contaminate samples, trip blanks should be distributed among all vehicles used in VOC sampling. Trip blanks do not need to be distributed among different field crews and sites; however, they should be collected throughout the time period of VOC sampling.

Field matrix spikes should be prepared when environmental concentrations of the spiked analyte are expected to be low (no more than 10 percent of the expected concentration in the spiked sample). Ideally, other chemical characteristics, particularly the concentration of organic carbon, should be similar to characteristics present when environmental concentrations of the spiked analyte are high. If pesticide or VOC samples are collected for more than 1 year, spike results should be evaluated after the first year to determine if a different (generally higher) spike concentration needs to be used during the second year.

Table 1. Collection frequencies for routine quality-control samples

$[--$, no samples required $]$

\begin{tabular}{|c|c|c|c|c|}
\hline \multirow{2}{*}{$\begin{array}{l}\text { Constituent } \\
\text { or group }\end{array}$} & \multicolumn{4}{|c|}{$\begin{array}{l}\text { Number of quality-control samples per total number of environmental samples } \\
\text { (at all surface-water sites, each year) }\end{array}$} \\
\hline & $\begin{array}{c}\text { Field } \\
\text { blanks }\end{array}$ & $\begin{array}{c}\text { Trip } \\
\text { blanks }\end{array}$ & $\begin{array}{l}\text { Replicate field } \\
\text { matrix spikes }\end{array}$ & Replicates \\
\hline Major ions & 1 per $30^{\mathrm{a}}$ & -- & -- & 1 per $20^{\mathrm{a}}$ \\
\hline Nutrients & 1 per $20^{\mathrm{a}}$ & -- & -- & 1 per $20^{\mathrm{a}}$ \\
\hline Suspended sediment & 1 per $30^{\mathrm{a}}$ & -- & -- & $\begin{array}{l}\text { With each inorganic or } \\
\text { pesticide replicate }\end{array}$ \\
\hline $\begin{array}{l}\text { Dissolved and suspended } \\
\text { organic carbon }\end{array}$ & 1 per $15-20^{\mathrm{a}, \mathrm{b}}$ & -- & -- & 1 per $15-20^{\mathrm{a}, \mathrm{b}}$ \\
\hline Pesticides & 1 per $20^{\mathrm{a}, \mathrm{c}}$ & -- & 1 set per site & 1 per $10^{\mathrm{d}}$ \\
\hline Volatile organic compounds & 1 per $10-20^{\mathrm{b}, \mathrm{c}, \mathrm{e}}$ & $1 \operatorname{per} 20^{f}$ & 1 set per site & 1 per $10-20^{b, c, d}$ \\
\hline Trace elements & 1 per $10-20^{\mathrm{a}, \mathrm{b}, \mathrm{c}}$ & -- & -- & 1 per $10-20^{\mathrm{a}, \mathrm{b}, \mathrm{c}, \mathrm{d}}$ \\
\hline
\end{tabular}


Replicates should be targeted at sites and times where concentrations of at least some target analytes are expected to exceed detection limits. If concentrations of all target analytes are expected to be less than detection, collection of replicates should be deferred until conditions are more favorable for detection. Attempt to collect replicates over the range of detectable concentrations expected within the study unit, but give greater emphasis to collecting replicates at high concentrations. Replicate samples need not be collected uniformly throughout the sampling period or at all surface-water sites; however, they should be scheduled to cover a broad range of hydrologic conditions. If surface-water samples are collected by more than one sampling team, each team should collect at least one replicate during the sampling period.

\section{DATA MANAGEMENT}

Consistent coding of routine QC samples among study units is essential. For this reason, datamanagement protocols have been developed for the NAWQA Program. Use the following instructions for coding information on ASR forms and into the National Water Information System (NWIS) data base. The most critical codes for proper sample identification are the station ID, sample medium, sample type, and the QADATA parameter codes.

Time coding of the sample is specified to distinguish among multiple samples at the same site visit, particularly field matrix spikes for which different lot numbers of spike solutions are used and field blanks for which different water types are used. Each type of sample (environmental, duplicate, inorganic field blank, organic field blank, canister blank, trip blank, pesticide spike and spike duplicate, or VOC spike and spike duplicate) that is coded for a particular site and date must have a unique time.

All routine QC samples should be associated with an environmental sample. Do not use fictitious station ID numbers for routine QC samples.

The NWIS data base cannot store lot numbers exactly as assigned for blank water or spike solutions. For consistency within the NAWQA Program, use parameter code 99104 (reference material or spike source code number) to store the first five numeric digits of the lot number associated with blanks or spikes. For example, PG water lot H16251, used for a pesticide blank, should be stored as 16251 ; VG lot 34116, used for a VOC blank, should be entered as 34116; IG water lot 94314 (\#18), bottle \#20, used for an inorganic blank, should be entered as 94314; and pesticide spike solution lot LA38492 should be entered as 38492.

The ASR and NWIS data base (QWDATA or QADATA) coding required for QC samples and associated environmental samples collected as part of the NAWQA Program are listed in appendix B.

\section{REFERENCES}

Capel, P.D., and Larson, S.J., 1996, Evaluation of selected information on splitting devices for water samples: U.S. Geological Survey Water-Resources Investigations Report 95-4141, 103 p.

Edwards, T.K., and Glysson, G.D., 1988, Field methods for measurement of fluvial sediment: U.S. Geological Survey Open-File Report 86-531, 118 p.

Shelton, L.R., 1994, Field guide for collecting and processing stream-water samples for the National Water-Quality Assessment Program: U.S. Geological Survey Open-File Report 94-455, 42 p. 
APPENDIXES 


\section{APPENDIX A. CONSTITUENTS INCLUDED IN NATIONAL WATER QUALITY LABORATORY SCHEDULES AND CODES REFERRED TO IN THIS REPORT}

Table A1. Pesticides analyzed in National Water Quality Laboratory schedules 2001 and 2010

\begin{tabular}{|c|c|c|}
\hline Watstore code & CAS number & Constituent \\
\hline 82660 & $579-66-8$ & 2,6-Diethylaniline \\
\hline 49260 & $34256-82-1$ & Acetochlor \\
\hline 46342 & $15972-60-8$ & Alachlor \\
\hline 39632 & 1912-24-9 & Atrazine \\
\hline 82686 & $86-50-0$ & Azinphos-methyl \\
\hline 82673 & $1861-40-1$ & Benfluralin \\
\hline 04028 & $2008-41-5$ & Butylate \\
\hline 82680 & $63-25-2$ & Carbaryl \\
\hline 82674 & $1563-66-2$ & Carbofuran \\
\hline 38933 & 2921-88-2 & Chlorpyrifos \\
\hline 04041 & $21725-46-2$ & Cyanazine \\
\hline 82682 & $1861-32-1$ & Dacthal \\
\hline 04040 & $6190-65-4$ & Deethylatrazine \\
\hline 39572 & $333-41-5$ & Diazinon \\
\hline 39381 & $60-57-1$ & Dieldrin \\
\hline 82677 & 298-04-4 & Disulfoton \\
\hline 82668 & 759-94-4 & EPTC \\
\hline 82663 & $55283-68-6$ & Ethalfluralin \\
\hline 82672 & $13194-48-4$ & Ethoprophos \\
\hline 04095 & $944-22-9$ & Fonofos \\
\hline 39341 & 58-89-9 & Lindane \\
\hline 82666 & $330-55-2$ & Linuron \\
\hline 39532 & $121-75-5$ & Malathion \\
\hline 39415 & $51218-45-2$ & Metolachlor \\
\hline 82630 & 21087-64-9 & Metribuzin \\
\hline 82671 & $2212-67-1$ & Molinate \\
\hline 82684 & 15299-99-7 & Napropamide \\
\hline 39542 & $56-38-2$ & Parathion \\
\hline 82667 & $298-00-0$ & Parathion-methyl \\
\hline 82669 & $1114-71-2$ & Pebulate \\
\hline 82683 & $40487-42-1$ & Pendimethalin \\
\hline 82664 & $298-02-2$ & Phorate \\
\hline 04037 & $1610-18-0$ & Prometon \\
\hline 04024 & $1918-16-7$ & Propachlor \\
\hline 82679 & $709-98-8$ & Propanil \\
\hline 82685 & $2312-35-8$ & Propargite \\
\hline 82676 & $23950-58-5$ & Propyzamide \\
\hline 04035 & $122-34-9$ & Simazine \\
\hline 82670 & $34014-18-1$ & Tebuthiuron \\
\hline 82665 & $5902-51-2$ & Terbacil \\
\hline 82675 & 13071-79-9 & Terbufos \\
\hline 82681 & $28249-77-6$ & Thiobencarb \\
\hline 82678 & $2303-17-5$ & Tri-allate \\
\hline 82661 & 1582-09-8 & Trifluralin \\
\hline 34253 & $319-84-6$ & alpha-HCH \\
\hline 34653 & $72-55-9$ & p,p'-DDE \\
\hline 82687 & $5264-55-3$ & Permethrin \\
\hline
\end{tabular}


Table A2. Pesticides analyzed in National Water Quality Laboratory schedules 2050 and 2051

\begin{tabular}{|c|c|c|}
\hline Watstore code & CAS number & Constituent \\
\hline 49295 & $90-15-3$ & 1-Naphthol \\
\hline 39742 & $93-76-5$ & $2,4,5-\mathrm{T}$ \\
\hline 39732 & $94-75-7$ & 2,4-D \\
\hline 38746 & $94-82-6$ & 2,4-DB \\
\hline 39762 & $93-72-1$ & 2-(2,4,5-Trichlorophenoxy) propanoic acid \\
\hline 49308 & $16655-82-6$ & 3-Hydroxycarbofuran \\
\hline 49299 & $534-52-1$ & 4, 6-Dinitro-2-methylphenol \\
\hline 49315 & $50594-66-6$ & Acifluorfen \\
\hline 49312 & $116-06-3$ & Aldicarb \\
\hline 49313 & $1646-88-4$ & Aldicarb sulfone \\
\hline 49314 & $1646-87-3$ & Aldicarb sulfoxide \\
\hline 38711 & $25057-89-0$ & Bentazon \\
\hline 04029 & $314-40-9$ & Bromacil \\
\hline 49311 & $1689-99-2$ & Bromoxynil \\
\hline 49310 & $63-25-2$ & Carbaryl \\
\hline 49309 & $1563-66-2$ & Carbofuran \\
\hline 49307 & $133-90-4$ & Chloramben \\
\hline 49306 & $1897-45-6$ & Chlorothalonil \\
\hline 49305 & $1702-17-6$ & Clopyralid \\
\hline 49304 & $887-54-7$ & Dacthal monoacid \\
\hline 38442 & $1918-00-9$ & Dicamba \\
\hline 49303 & $1194-65-6$ & Dichlobenil \\
\hline 49302 & $120-36-5$ & Dichlorprop \\
\hline 49301 & $88-85-7$ & Dinoseb \\
\hline 49300 & $330-54-1$ & Diuron \\
\hline 49298 & $66230-04-4$ & Esfenvalerate \\
\hline 49297 & $101-42-8$ & Fenuron \\
\hline 38811 & $2164-17-2$ & Fluometuron \\
\hline 38478 & $330-55-2$ & Linuron \\
\hline 38482 & $94-74-6$ & MCPA \\
\hline 38487 & $94-81-5$ & MCPB \\
\hline 38501 & $2032-65-7$ & Methiocarb \\
\hline 49296 & $16752-77-5$ & Methomyl \\
\hline 49294 & $555-37-3$ & Neburon \\
\hline 49293 & 27314-13-2 & Norflurazon \\
\hline 49292 & $19044-88-3$ & Oryzalin \\
\hline 38866 & $23135-22-0$ & Oxamyl \\
\hline 49291 & $1918-02-1$ & Picloram \\
\hline 49236 & $122-42-9$ & Propham \\
\hline 38538 & $114-26-1$ & Propoxur \\
\hline 49235 & $55335-06-3$ & Triclopyr \\
\hline
\end{tabular}


Table A3. Volatile organic compounds analyzed in National Water Quality Laboratory schedule 2020

\begin{tabular}{|c|c|c|}
\hline Watstore code & CAS number & Constituent \\
\hline \multicolumn{3}{|c|}{ Primary target analytes } \\
\hline 32101 & $75-27-4$ & Bromodichloromethane \\
\hline 32102 & $56-23-5$ & Tetrachloromethane \\
\hline 32103 & $107-06-2$ & 1,2-Dichloroethane \\
\hline 32104 & $75-25-2$ & Tribromomethane \\
\hline 32105 & $124-48-1$ & Dibromochloromethane \\
\hline 32106 & $67-66-3$ & Trichloromethane \\
\hline 34010 & $108-88-3$ & Methylbenzene \\
\hline 34030 & $71-43-2$ & Benzene \\
\hline 34210 & $107-02-8$ & 2-Propenal \\
\hline 34215 & $107-13-1$ & 2-Propenenitrile \\
\hline 34301 & $108-90-7$ & Chlorobenzene \\
\hline 34311 & $75-00-3$ & Chloroethane \\
\hline 34371 & $100-41-4$ & Ethylbenzene \\
\hline 34396 & $67-72-1$ & $1,1,1,2,2,2$-Hexachloroethane \\
\hline 34413 & $74-83-9$ & Bromomethane \\
\hline 34418 & $74-87-3$ & Chloromethane \\
\hline 34423 & $75-09-2$ & Dichloromethane \\
\hline 34475 & $127-18-4$ & Tetrachloroethene \\
\hline 34488 & $75-69-4$ & Trichlorofluoromethane \\
\hline 34496 & $75-34-3$ & 1,1-Dichloroethane \\
\hline 34501 & $75-35-4$ & 1,1-Dichloroethene \\
\hline 34506 & $71-55-6$ & 1,1,1-Trichloroethane \\
\hline 34511 & $79-00-5$ & 1,1,2-Trichloroethane \\
\hline 34536 & $95-50-1$ & 1,2-Dichlorobenzene \\
\hline 34541 & $78-87-5$ & 1,2-Dichloropropane \\
\hline 34546 & $156-60-5$ & trans-1,2-Dichloroethene \\
\hline 34551 & $120-82-1$ & 1,2,4-Trichlorobenzene \\
\hline 34566 & $541-73-1$ & 1,3-Dichlorobenzene \\
\hline 34571 & $106-46-7$ & 1,4-Dichlorobenzene \\
\hline 34668 & $75-71-8$ & Dichlorodifluoromethane \\
\hline 34696 & $91-20-3$ & Naphthalene \\
\hline 34699 & $10061-02-6$ & trans-1,3-Dichloropropene \\
\hline 34704 & $10061-01-5$ & cis-1,3-Dichloropropene \\
\hline 39175 & $75-01-4$ & Chloroethene \\
\hline 39180 & $79-01-6$ & Trichloroethene \\
\hline 39702 & $87-68-3$ & Hexachlorobutadiene \\
\hline 50002 & $593-60-2$ & Bromoethene \\
\hline 50004 & $637-92-3$ & Ethyl tert-butyl ether \\
\hline 50005 & $994-05-8$ & tert-Amyl methyl ether \\
\hline 77093 & $156-59-2$ & cis-1,2-Dichloroethene \\
\hline 77128 & $100-42-5$ & Ethenylbenzene \\
\hline 77135 & $95-47-6$ & 1,2-Dimethylbenzene \\
\hline 77222 & $95-63-6$ & 1,2,4-Trimethylbenzene \\
\hline 77223 & $98-82-8$ & (1-Methylethyl)benzene \\
\hline 77224 & $103-65-1$ & n-Propylbenzene \\
\hline 77342 & $104-51-8$ & n-Butylbenzene \\
\hline 77443 & $96-18-4$ & 1,2,3-Trichloropropane \\
\hline 77613 & $87-61-6$ & 1,2,3-Trichlorobenzene \\
\hline
\end{tabular}


Table A3. Volatile organic compounds analyzed in National Water Quality Laboratory schedule 2020-Continued

\begin{tabular}{|c|c|c|}
\hline Watstore code & CAS number & Constituent \\
\hline \multicolumn{3}{|c|}{ Primary target analytes-Continued } \\
\hline 77651 & $106-93-4$ & 1,2-Dibromoethane \\
\hline 77652 & $76-13-1$ & 1,1,2-Trichloro-1,2,2-trifluoroethane \\
\hline 78032 & $1634-04-4$ & Methyl tert-butyl ether \\
\hline 81577 & $108-20-3$ & Diisopropyl ether \\
\hline \multirow[t]{2}{*}{82625} & $96-12-8$ & 1,2-Dibromo-3-chloropropane \\
\hline & $106-42-3$ & 1,3-Dimethylbenzene \\
\hline 85795 & $108-38-3$ & 1,4-Dimethylbenzene \\
\hline \multicolumn{3}{|c|}{ Other analytes } \\
\hline 30217 & $74-95-3$ & Dibromomethane \\
\hline 34516 & $79-34-5$ & 1,1,2,2-Tetrachloroethane \\
\hline 49991 & $96-33-3$ & Methyl acrylate \\
\hline 49999 & $488-23-3$ & 1,2,3,4-Tetramethylbenzene \\
\hline 50000 & $527-53-7$ & 1,2,3,5-Tetramethylbenzene \\
\hline 73547 & $110-57-6$ & trans-1,4-Dichloro-2-butene \\
\hline 73570 & $97-63-2$ & Ethyl methacrylate \\
\hline 77041 & $75-15-0$ & Carbon disulfide \\
\hline 77057 & $108-05-4$ & Vinyl acetate \\
\hline 77103 & $591-78-6$ & 2-Hexanone \\
\hline 77168 & $563-58-6$ & 1,1-Dichloropropene \\
\hline 77170 & $594-20-7$ & 2,2-Dichloropropane \\
\hline 77173 & $142-28-9$ & 1,3-Dichloropropane \\
\hline 77220 & $611-14-3$ & 2-Ethyltoluene \\
\hline 77221 & $526-73-8$ & 1,2,3-Trimethylbenzene \\
\hline 77226 & $108-67-8$ & 1,3,5-Trimethylbenzene \\
\hline 77275 & $95-49-8$ & 1-Chloro-2-methylbenzene \\
\hline 77277 & $106-43-4$ & 1-Chloro-4-methylbenzene \\
\hline 77297 & $74-97-5$ & Bromochloromethane \\
\hline 77350 & $135-98-8$ & (1-Methylpropyl)benzene \\
\hline 77353 & $98-06-6$ & (1,1-Dimethylethyl)benzene \\
\hline 77356 & $99-87-6$ & 1-Isopropyl-4-methylbenzene \\
\hline 77424 & $74-88-4$ & Iodomethane \\
\hline 77562 & $630-20-6$ & 1,1,1,2-Tetrachloroethane \\
\hline 78109 & $107-05-1$ & 3-Chloro-1-propene \\
\hline 78133 & $108-10-1$ & 4-Methyl-2-pentanone \\
\hline 81552 & $67-64-1$ & Acetone \\
\hline 81555 & $108-86-1$ & Bromobenzene \\
\hline 81576 & $60-29-7$ & Diethyl ether \\
\hline 81593 & $126-98-7$ & Methyl acrylonitrile \\
\hline 81595 & $78-93-3$ & 2-Butanone \\
\hline 81597 & $80-62-6$ & Methyl methacrylate \\
\hline 81607 & 109-99-9 & Tetrahydrofuran \\
\hline
\end{tabular}




\section{APPENDIX B. ANALYTICAL SERVICES REQUEST AND NATIONAL WATER INFORMATION SYSTEM DATA-BASE CODING REQUIRED FOR QUALITY-CONTROL SAMPLES AND ASSOCIATED ENVIRONMENTAL SAMPLES COLLECTED AS PART OF THE NATIONAL WATER-QUALITY ASSESSMENT PROGRAM}

\section{Blanks}

\section{Environmental Sample Associated with the Blank}

ASR coding

TIME - Time of sample collection rounded to nearest 10-minute interval (HH:X0)

SAMPLE MEDIUM - 9 (surface water)

SAMPLE TYPE - 9 (regular)

QWDATA coding

Parameter 71999 (sample purpose) - 15 (NAWQA)

Parameter 99111 (QA data associated with sample) - 10 (blank)

\section{Field Blank}

ASR coding

STATION ID and DATE - Same as environmental sample

TIME - Time of preparation (different from environmental sample) (NOTE: Blanks made from different source solutions must have unique times.)

SAMPLE MEDIUM - Q (QA sample - artificial)

SAMPLE TYPE - 2 (blank)

LOGIN COMMENTS - "PREVIOUS SAMPLE AT: previous station ID, date/time"

QADATA coding

Parameter 71999 (sample purpose) - 15 (NAWQA)

Inorganic blanks:

Parameter 99100 (type of blank solution) - 10 (IG water)

Parameter 99101 (source of blank solution) - 80 (Ocala)

Organic blanks:

Parameter 99100 (type of blank solution) - 40 (PG water) or 50 (VG water)

Parameter 99101 (source of blank solution) - 10 (NWQL)

Parameter 99102 (type of blank sample) - 100 (field)

Parameter 99104 (blank lot number) - First five digits of lot number

\section{Canister Blank}

ASR coding

STATION ID and DATE - Same as environmental sample

TIME - 1 minute earlier than the VOC field blank

SAMPLE MEDIUM - Q (QA sample - artificial)

SAMPLE TYPE - B (other QA)

QADATA coding

Parameter 71999 (sample purpose) - 15 (NAWQA)

Parameter 99100 (type of blank solution) - 50 (VG water)

Parameter 99101 (source of blank solution) - 10 (NWQL)

Parameter 99102 (type of blank sample) - 200 (other)

Parameter 99104 (blank lot number) - First five digits of lot number

\section{Trip Blank}

ASR coding

STATION ID and DATE - Same as environmental sample

TIME - 1 minute later than the VOC field blank

SAMPLE MEDIUM - Q (QA sample - artificial)

SAMPLE TYPE - 2 (blank)

QADATA coding

Parameter 71999 (sample purpose) - 15 (NAWQA)

Parameter 99100 (type of blank solution) - 50 (VG water)

Parameter 99101 (source of blank solution) - 10 (NWQL)

Parameter 99102 (type of blank sample) - 30 (trip)

Parameter 99109 (start date YMMDD) - Date trip blanks received from NWQL (for example, 60522, for May 22, 1996)

Parameter 99110 (end date YMMDD) - Date trip blanks shipped to NWQL (for example, 60530, for May 30, 1996) 


\section{Spikes}

\section{Primary Environmental Sample Associated with the Spikes}

ASR coding

TIME - Time of collection rounded to nearest 10-minute interval (HH:X0) (NOTE: The VOC samples must have a time different from other samples.)

SAMPLE MEDIUM - 9 (surface water)

SAMPLE TYPE - 9 (regular), or 7 (replicate) if replicate environmental samples are used to estimate background concentrations

QWDATA coding

Parameter 71999 (sample purpose) - 15 (NAWQA)

Parameter 99111 (QA data associated with sample) 40 (spike) or 100 (more than one type) if replicate environmental samples are used to estimate background concentrations

\section{Duplicate Environmental Sample Associated with the Spikes}

ASR coding

STATION ID and DATE - Same as primary environmental sample associated with the spikes

TIME - 1 minute later than primary environmental sample (HH:X1) (NOTE: The VOC samples must have a time different from other samples.)

SAMPLE MEDIUM - R (QA sample - surface water)

SAMPLE TYPE - 7 (replicate) Q

QWDATA coding

Parameter 71999 (sample purpose) - 15 (NAWQA)

Parameter 99105 (replicate type) - 30 (split) for pesticides or 10 (concurrent) for VOC's

\section{Field Matrix Spike}

ASR coding

STATION ID and DATE - Same as primary environmental sample associated with the spikes

TIME - Schedule 2001/2010: 2 minutes later than environmental sample (HH:X2)

Schedule 2050/2051: 4 minutes later than environmental sample (HH:X4)

Schedule 2020: 6 minutes later than environmental sample (HH:X6)
SAMPLE MEDIUM - R (QA sample - surface water)

SAMPLE TYPE - 1 (spike)

LOGIN COMMENTS - "SH___ spike lot number" (for example - SH2001: LA38492)

QADATA coding

Parameter 71999 (sample purpose) - 15 (NAWQA)

Parameter 99104 (spike lot number) - Enter first five numeric digits of lot number

Parameter 99105 (replicate type) - 30 (split) for pesticides or 10 (concurrent) for VOC's

Parameter 99106 (spike type) - 10 (field)

Parameter 99107 (spike source) - 10 (NWQL)

Parameter 99108 (spike volume) - volume used, in milliliters $(100 \mu \mathrm{L}=0.1 \mathrm{~mL})$

\section{Field Matrix Spike Duplicate}

ASR coding

STATION ID and DATE - Same as primary environmental sample associated with the spikes

TIME - Schedule 2001/2010: 3 minutes later than environmental sample (HH:X3)

Schedule 2050/2051: 5 minutes later than environmental sample (HH:X5)

Schedule 2020: 7 minutes later than environmental sample (HH:X7)

SAMPLE MEDIUM - R (QA sample - surface water)

SAMPLE TYPE - 1 (spike)

LOGIN COMMENTS - "SH___ : spike lot number" (for example - SH2001: LA38492)

QADATA coding

Parameter 71999 (sample purpose) - 15 (NAWQA)

Parameter 99104 (spike lot number) - Enter first five numeric digits of lot number

Parameter 99105 (replicate type) - 30 (split) for pesticides or 10 (concurrent) for VOC's

Parameter 99106 (spike type) - 10 (field)

Parameter 99107 (spike source) - 10 (NWQL)

Parameter 99108 (spike volume) - volume used, in milliliters $(100 \mu \mathrm{L}=0.1 \mathrm{~mL})$ 


\section{Replicates}

\section{Primary Environmental Sample}

ASR coding

TIME - Time of collection rounded to nearest 10-minute interval (HH:X0) (NOTE: The VOC samples must have a time different from other samples.)

SAMPLE MEDIUM - 9 (surface water)

SAMPLE TYPE - 7 (replicate)

QWDATA coding

Parameter 71999 (sample purpose) - 15 (NAWQA)

Parameter 99105 (replicate type) - 30 (split) for inorganic constituents or pesticides or 10 (concurrent) for DOC, SOC, or VOC's. (If either inorganic constituents or pesticide replicates are prepared at the same time as DOC and SOC replicates, code this parameter 30.)

Parameter 99111 (QA data associated with sample) - 30 (replicate sample)

\section{Duplicate Environmental Sample}

ASR coding

STATION ID and DATE - Same as primary environmental sample

TIME - 1 minute later than primary environmental sample (HH:X1)

SAMPLE MEDIUM - R (QA sample - surface water)

SAMPLE TYPE - 7 (replicate)

QADATA coding

Parameter 71999 (sample purpose) - 15 (NAWQA)

Parameter 99105 (replicate type) - 30 (split) for inorganic constituents or pesticides or 10 (concurrent) for DOC, SOC, or VOC's. (If either inorganic constituents or pesticide replicates are prepared at the same time as DOC and SOC replicates, code this parameter 30.) 
